\title{
Screening of Risk Factors of Hypertension among Urban and Rural Populations of District-Hapur
}

\author{
${ }^{1}$ Drviveksinha, ${ }^{2}$ Dr Poonam Kachhawa, \\ ${ }^{I}$ Associate Professor, Department Of Biochemistry,Saraswathi Institute Of Medical Sciences, Hapur Uttar \\ Pradesh, India \\ ${ }^{2}$ Assistant Professor, Department Of Biochemistry, Saraswathi Institute Of Medical Sciences, Hapur, Uttar \\ Pradesh \\ *Corresponding author: Drviveksinha *
}

\begin{abstract}
:
Introduction:Hypertension is an important worldwide public-health challenge because of its high frequency and concomitant risks of cardiovascular and kidney disease. Hypertension is the new era pandemic which is the leading cause of mortality in the world and is ranked third as a cause of disability-adjusted life years. Various risk factors are implicated in the development of hypertension and there are differences in these risk factors in urban and rural populations depending on the level of development and epidemiological transition.

Aims \& Objective:The preesent study was undertaken to estimate the prevalence of hypertension and identify \& compare some socio-demographic and lifestyle risk factors associated with hypertension in urban and rural populations of Hapur.

Materials and methods: It's a community based cross-sectional study in which 300 adults each were randomly selected from urban and rural populations of Hapur using modified cluster sampling method. Selected individuals were examined and interviewed using a structured, pre-tested questionnaire. Two Blood Pressure readings were recorded using mercury sphygmomanometer in the sitting position and the mean of two was considered for analysis. Data entry and analysis was done using SPSS for windows version 8.1.

Result:Most of the study population belonged to age group of 20-29 yrs (27.5\%) followed by 30-39 yrs (24.5\%). $41.2 \%$ of the study population was constituted by males and the rest $58.8 \%$ by females. Majority of the study population belonged to middle class (58\%) followed by upper lower class (18\%). The prevalence of hypertension was $21 \%$ in the present study, which is comparable to the estimates given by World Health Organization (23\%). Around 33.7\% of the population had blood pressure in the normal range and $45.3 \%$ of the population had pre-hypertension. The prevalence of hypertension was $23.7 \%$ in the urban areas and $18.3 \%$ in the rural areas. This difference was found to be statistically insignificant.

Conclusion: The present study identified as risk factors for the development of hypertension - increasing age, sedentary occupation, higher socio-economic status, extra salt intake, family history of hypertension, reduced physical activity, tobacco smoking, smokeless tobacco consumption, alcohol consumption, BMI $\geq 25$ and high waist-hip ratio.
\end{abstract}

Keywords: Hypertension,prevalence, riskfactors,population

\section{Introduction}

- Hypertension is the new era pandemic which is the leading cause of mortality in the world and is ranked third as a cause of disability-adjusted life years.[1]

- The World Health Organization and the seventh report of the Joint National Committee on prevention, detection, evaluation, and treatment of high blood pressure (JNC-7) defines hypertension as systolic blood pressure more than or equal to $140 \mathrm{mmHg}$ and/or diastolic blood pressure more than or equal to 90 mmHg.[2,3]

- Hypertension has become an important worldwide public-health challenge because of its high prevalence and concomitant risks of coronary artery disease, congestive heart failure, stroke, end stage renal disease, dementia and blindness.[4,8] People with hypertension posses two fold higher risk of developing coronary artery disease, four times higher risk of congestive heart failure and seven times higher risk of cerebrovascular disease compared to normotensive people. $[9,10]$

- Because of changes in life style, changes in environment and increased life expectancy the problem of hypertension is on the rise. Recent data suggests that non-communicable diseases are already the commonest cause of death in many parts of rural India.[20,22] This is plausible as, apart from improvements in life expectancy, the greater interconnectedness increasingly allows rural populations to adopt urban lifestyles without migration to urban areas.[22,23] 


\section{Risk factors associated with Hypertension}

- There are various risk factors associated with hypertension; some of the known risk factors for primary hypertension like age, heredity, and gender are non-modifiable. However, the majority of the other risk factors like tobacco use, alcohol use, unhealthy diet, physical inactivity, overweight and obesity can be effectively prevented.[24] There are differences in these risk factors in urban and rural populations depending on the level of development and epidemiological transition.

- The control of hypertension will require modification of its risk factors and hence necessitates identifying the various risk factors associated with hypertension in the urban and rural populations of India.

- Hypertension is an "ice-berg" disease and scarcity of data is sometimes understood as non-existence of the problem.[26] There is paucity of data on hypertension prevalence in many parts of India specially the rural areas. Thus, burden of hypertension in these populations might be underestimated and might leave the disease undiagnosed and untreated.

- Estimating the prevalence of hypertension and its risk factors in both the urban and rural populations is very crucial as this forms the basis for planning of primary and secondary prevention of hypertension. Hence this field based cross-sectional study was undertaken.

\section{Objectives}

- To estimate and compare the prevalence of hypertension in urban and rural adult populations of Hapur Uttar Pradesh.To identify and compare some sociodemographic and lifestyle risk factors associated with hypertension in urban and rural populations of Uttar Pradesh.

\section{Methodology}

\section{Materials And Methods}

Study Area:The study was conducted in rural and urban field practice area of Pilkhuwa and Hapur District, under Department of BIOCHEMISTRY, Saraswathi Institute of Medical Sciences, Hapur [U.P]. The area comprised of four major areas i.e. Khera, Sikhera, Saddikpura and Mukeempur. The study was conducted in all four areas.

Study design:This is a field based cross-sectional, comparative study.

Study period:The study was conducted from March 2016 to Dec. 2016. Data analysis and report writing was done from Dec 2016 to Feb 2017.

Study Population: The study was carried out in urban and rural field practice area of Hapur and Pilkhuwa. All the people with age group 20 years and above living in the study area were eligible to participate in the study.

\section{Tools used in collection of data:}

- Pre-tested semi-structured Questionnaire to assess:Socio-demographic characteristics of the study participants.

- General physical and CVS examination in study subjects.

- $\quad$ Risk factors associated with Hypertension.

\section{Statistical Analysis}

The data collection was tabulated,coded,andanallyzed using Microsoft word SPSS for windows version 8.1

\begin{tabular}{|l|l|l|}
\hline BLOOD PRESSURE CLASSIFICATION & NO. & $\%$ \\
\hline NORMAL & 202 & 33.7 \\
\hline PRE-HYPERTENSION & 272 & 453 \\
\hline Stage 1 Hypertension & 97 & 162 \\
\hline Stage 2 Hypertension & 29 & 4.8 \\
\hline TOTAL & 600 & 100 \\
\hline
\end{tabular}

Table 1: Distribution Of Study Subjects Based On Jnc-7classification 
Table 2.Prevalance of hypertension in urban and rural study population

\begin{tabular}{|l|l|l|l|}
\hline Residence & No. & Hypertensive \% & Normotensive \% \\
\hline Urban & 300 & $71(23.7)$ & $229(76.3)$ \\
\hline Rural & 300 & $55(18.3)$ & $245(81.7)$ \\
\hline Total & 600 & $126(21)$ & $474(79)$ \\
\hline
\end{tabular}

Table 3.Distribution of subjects according to blood pressure status and Age

\begin{tabular}{|l|l|l|l|}
\hline Age (yrs) & No. & Hypertensive \% & Normotensive \% \\
\hline $20-29$ & 165 & $10(6)$ & $155(94)$ \\
\hline $30-39$ & 147 & $16(10.8)$ & $131(89.2)$ \\
\hline $40-49$ & 123 & $27(21.9)$ & $96(78.2)$ \\
\hline $50-59$ & 82 & $32(39)$ & $51(61)$ \\
\hline $60-69$ & 62 & $30(48.4)$ & $32(51.6)$ \\
\hline Upto 70 & 21 & $11(52.4)$ & $10(47.6)$ \\
\hline Total & 600 & $126(21)$ & $474(79)$ \\
\hline
\end{tabular}

Table 4 : Distribution of subjects according to blood pressure status and gender

\begin{tabular}{|l|l|l|l|}
\hline Gender & No. & Hypertensive\% & Normotensive\% \\
\hline Male & 247 & $58(23.5)$ & $189(76.5)$ \\
\hline Females & 353 & $68(19.2)$ & $285(80.8)$ \\
\hline Total & 600 & $126(21)$ & $474(79)$ \\
\hline
\end{tabular}

Table 5.Urban and rural distribution of subjects by blood pressure status andgender

\begin{tabular}{|l|l|l|l|l|}
\hline Gender & No. & URBAN $($ HTN \% ) & No. & RURAL (HTN \% ) \\
\hline Males & 121 & $32(26.4)$ & 126 & $26(20.6)$ \\
\hline Females & 179 & $39(21.8)$ & 174 & $29(16.7)$ \\
\hline Total & 300 & $71(23.7)$ & 300 & $55(18.3)$ \\
\hline
\end{tabular}

\section{Discussion}

- The present study was conducted to estimate and compare the prevalence of hypertension in urban and rural populations of Hapur and to identify \& compare some socio-demographic and lifestyle risk factors associated with hypertension in urban and rural populations of Hapur.A total of 600 subjects were selected, which included 300 each from urban and rural areas of Hapur respectively. Most of the study population belonged to age group of $20-29$ yrs $(27.5 \%)$ followed by $30-39$ yrs (24.5\%). $41.2 \%$ of the study population was constituted by males and the rest $58.8 \%$ by females. Majority of the study population belonged to middle class $(58 \%)$ followed by upper lower class $(18 \%)$.

- Prevalence of hypertension:Following JNC-7 and WHO definition of hypertension, the prevalence of hypertension in the present study was $21 \%$. Around $33.7 \%$ of the population had blood pressure in the normal range and $45.3 \%$ of the population had pre-hypertension. The findings of the study are comparable to $\mathrm{WHO}$ estimates which gives a $23 \%$ prevalence of hypertension in India.

- Prevalence of hypertension in rural areas:The prevalence of hypertension in rural areas was $18.3 \%$. The prevalence rates of the present study differed from those given by Office of Register General of India (10\%) and WHO $(22.6 \%)[11,17]$. Depending on the rural areas selected and the methodology used other researchers have found a prevalence of hypertension in rural Indian areas ranging from $7 \%$ to $19 \%$.

- Prevalence of hypertension in urban areas:The prevalence of hypertension in urban areas was $23.7 \%$. The prevalence rates were similar to those given by Office of Register General of India (25\%) and WHO 
(23.1\%).[11,17] Based on the difference in the methodology used other researchers have found a prevalence of hypertension in urban Indian areas ranging from $20 \%$ to $40 \%$.

- Association between hypertension and age :The present study found increasing age to be an important non-modifiable risk factor for the development of hypertension. The prevalence of hypertension was $6 \%$ in the age group of $20-29 \mathrm{yrs}$, which increased to $52.4 \%$ for people of aged $\geq 70 \mathrm{yrs}$. There was a sharp increase in the prevalence of hypertension after the age of 50 years. The increase in blood pressure with age was found to be similar in both the urban and rural areas. The main reason for increase in blood pressure with increase in age is that arteries and arterioles become less elastic due to atherosclerotic changes as people age. Changes in lifestyle and stress are also important contributors. Almost all the studies done to identify the risk factors of hypertension have inferred that age is a significant risk factor for the development of hypertension. The prevalence of hypertension was $12.9 \%$ for the age group $25-39$ yrs which increased to $57.5 \%$ for the age group $55-64$ years.

- Association between hypertension and gender :In the present study males had a higher prevalence of hypertension compared to females. The prevalence of hypertension was $23.5 \%$ in males and $19.2 \%$ in females, but this difference was found to be statistically insignificant. In urban areas the prevalence of hypertension was $26.4 \%$ in males and $21.8 \%$ in females. In the rural areas the prevalence of hypertension was $20.6 \%$ in males and $16.7 \%$ in females.A large number of epidemiological studies have inferred that prevalence of hypertension is more in males as compared to females. This is because; during adolescent and middle aged males have a higher blood pressure compared to females. The female hormones estrogen and progesterone have a protective effect on blood pressure. Later in life this difference diminishes mainly because of the postmenopausal changes.In the present study thought there is difference in prevalence of hypertension in males and females it is not statistically significant, this is most probably because there were more number of postmenopausal women involved in the study

\section{Conclusion}

- The prevalence of hypertension was $21 \%$ in the present study, which is comparable to the estimates given by World Health Organization $(23 \%)$. Around $33.7 \%$ of the population had blood pressure in the normal range and $45.3 \%$ of the population had pre-hypertension.

- The present stydy identified as risk factors for the development of hypertension - increasing age, sedentary occupation, higher socio-economic status, extra salt intake, family history of hypertension, reduced physical activity, tobacco smoking, smokeless tobacco consumption, alcohol consumption, BMI $\geq 25$ and high waist-hip ratio.

- $\quad$ Family history of hypertension, BMI $\geq 25$ and high waist-hip ratio were found to be predominant risk factors for hypertension in the urban areas.

- $\quad$ Source ofSupport:Nil, Conflict of Intrest: None Declared

\section{Reference}

[1]. Ezzati M, Lopez AD, Rodgers A, Vander Hoorn S, Murray CJ. Selected major risk factors and global and regional burden of disease. Lancet 2000;360:1347-60.

[2]. WHO. World Health Organization/International Society of Hypertension statement on management of hypertension. J hypertens $2003 ; 21: 1983-92$

[3]. Chobanion AV, Bakris GL, Black HR. The seventh report of the joint national committee on prevention, detection, evaluation, and treatment of high blood pressure, The JNC 7 report. JAMA 2003;289:2560-72.

[4]. He J, Whelton PK. Epidemiology and prevention of hypertension. Med ClinNorth Am 1997;81:1077-97.

[5]. Whelton PK. Epidemiology of hypertension. Lancet 1994; 344:101-06.

[6]. Kearney PM, Whelton M, Reynolds K, Munter P, Whelton PK, He J: Global

[7]. burden of hypertension: analysis of worldwide data. Lancet 2005;365:217-23

[8]. World Health Report 2002: Reducing Risks, Promoting Healthy life. WHO, 2002

[9]. WHO. Integrated management of cardiovascular risk: report of a WHO meeting, Geneva. WHO, 2002:9-12

[10]. Stamler J. Blood pressure and high blood pressure: Aspects of risk. Hypertension 1991;18:107.

[11]. Flack JM, Nearton, Grimm R. Blood pressure and mortality among men with prior myocardial infarction: Multiple risk factor intervention trial research group. Circulation 1995;92:2437-45.

[12]. World Health Organization. World health statistics 2012. WHO, 2012 [cited 2012 Apr 23]. Available from http://www.who.int/gho/publications/world_health_statistics/2012/en/

[13]. Anderson, G.F. \& Chu, E. Expanding priorities-confronting chronic disease in countries with low income. N Engl J Med 2007;356:209-11.

[14]. Burt VL., Whelton P, Roccella EJ, Brown C, Cutler JA, Higgins M, et al. Prevalence of hypertension in the US adult population. Results from the Third National Health and Nutrition Examination Survey. Hypertension 1991;25(3):305-13.

[15]. World Health Report. Reducing risks, promoting healthy life. WHO, 2005 [cited 2012 Feb 18]. Available from http://www.who.int/whr/2002/en/whr02_en.pdf.

[16]. World Health Organization. Preventing chronic diseases: a vital investment. WHO, 2005.

[17]. World Health Organization. 2008-2013 action plan for the global strategy for the prevention and control of non-communicable diseases: prevent and control cardiovascular diseases, cancers, chronic respiratory diseases and diabetes. WHO, 2008

[18]. Report on causes of deaths in India 2001-2003. Office of the Registrar General of India, Govt. of India, 2010.

[19]. World Health Organization, Preventing chronic diseases: a vital investment. WHO, 2005. 
[20]. Gupta R. Rethinking Diseases of Affluence; Coronary Heart Disease in Developing Countries. South Asian Journal of Preventive cardiology 2006 Apr-Jun;10(2):65-78.

[21]. Joshi R, Cardona M, Iyengar S, Sukumar A, Raju CR, Raju KR, et al. Chronic diseases now a leading cause of death in rural India-mortality data from the Andhra Pradesh Rural Health Initiative. Int J Epidemiol 2006;35:1522-9.

[22]. Gajalakshmi V, Peto R. Verbal autopsy of 80,000 adult deaths in Tamil Nadu, South India. BMC Public Health 2004;4:47.

[23]. Beaglehole R, Yach D. Globalisation and the prevention and control of non-communicable disease: the neglected chronic diseases of adults. Lancet 2003;362:903-8.

[24]. Reddy KS. Cardiovascular diseases in the developing countries: dimensions, determinants, dynamics and directions for public health action. Public HealthNutr2002;5:231-7.

[25]. WHO. Health expectancy is more important than life expectancy - Message from the WHO Director General on The World Health Report 1998, Geneva, Switzerland. WHO, 1998;5-6.

[26]. Kapoor S, Tyagi R, Saluja K, Chaturvedi A and Kapoor AK. Emerging health threats among a primitive tribal group of Central India. Journal of PublicHealth and Epidemiology 2010 Apr;2(2):13-9.

[27]. World Health Organization. Prospects of Research on non-communicable diseases in the African sub-region. WHO, 2008 [cited on Feb 17]. Available from: http://www.afro.who.int/dpm/rpc/publications/ ncdwok.pdf.

[28]. Giuliani ER, Valentin F, Gersh BJ, McGoon MD, McGoon DC. Cardiology: Fundamental and practices. $2^{\text {nd }}$ Ed. St.Louis (USA): Mosby year book; 1991.

[29]. Medicine under pressure. The history of hypertension. Sweden: Astra Hassle; 1996.

[30]. Wasir HS. Need for National hypertension control programme. Indian HeartJournal 1995;47:409-10.

[31]. Sleight P, Freis E. Cardiology-Hypertension. $2^{\text {nd }}$ Ed. Butterworth and Co: London; 1982 